\title{
Reply to commentary on Zika: An Ongoing Threat to Women and Infants
}

\author{
Réplica ao comentário sobre o artigo Zika: \\ An Ongoing Threat to Women and Infants
}

Respuesta al comentario sobre el artículo Zika: An Ongoing Threat to Women and Infants

\author{
Beatriz Macedo Coimbra dos Santos 1 \\ Flavio Codeço Coelho 1 \\ Margaret Armstrong 1 \\ Valeria Saraceni 2 \\ Cristina Lemos 2
}

doi: 10.1590/0102-311X00192318

Since the large Brazilian epidemic of 2015/2016, the Zika virus (ZIKV) has been slowly fading from the radar of important public health concerns in the country. Nevertheless, a number of important questions remained unanswered since then. The motivation behind this research was to look at the post-epidemic characteristics of Zika transmission in search for a clear understanding about the risks posed by ZIKV separate from the potential confounding scenario of 2016 where it co-circulated with Dengue virus (DENV) and Chikungunya virus (CHIKV).

A year later from the beginning of this study, these concerns still permeate the literature and the preliminary results we obtained are still relevant.

The threat Zika virus imposes on women and infants remains. Besides the risk of congenital syndrome, the Zika-related neurological complications, although rare, haunt the population at risk. The arbovirus is still circulating in Brazil in 2018, with 7,071 reported cases, $41.5 \%$ of those confirmed, according to the Brazilian Ministry of Health Epidemiological Bulletin (year 2018; week 34).

The interactions between demography and immunological dynamics of arboviruses can explain the unexpected exposure of infants we reported. In Nicaragua this has been well characterized for Dengue. Balmaseda et al. 1 have shown that young children are disproportionately affected due to their lack of immunity from previous epidemics and also that dengue seropositivity increases in this age group as time goes by.

The increased exposure of infants may be more than just an effect of demography. It may be related to the actual specificities of Zika transmission. By explicitly modeling both vectorial and sexual routes of transmission for Zika, we have demonstrated 2 that even during non-epidemic transmission $\left(\mathrm{R}_{0}<1\right)$ the risk to women of reproductive age remains high. Since infants are in constant contact with their mothers, they have an increased risk of being infected, either vectorially or even through nursing, since ZIKV is also in breast milk.

Upon being exposed, infants are at risk of developing serious neurological complications from ZIKV 3 and other arboviruses. Therefore we reiterate the importance of a careful look at arboviral epidemics by age and gender so that we can continue to unravel their patterns of spread and better protect the populations at risk.
1 Fundação Getulio Vargas, Rio de Janeiro, Brasil. 2 Secretaria Municipal de Saúde, Rio de Janeiro, Brasil.

Correspondence B. M. C. Santos Fundação Getulio Vargas.

Praia de Botafogo 190,

Rio de Janeiro, $R J$ 22250-900, Brasil. beatrizmcoimbra@outlook.com 


\section{Contributors}

All authors contributed to the writing and data analysis.

\section{References}

1. Balmaseda A, Standish K, Mercado JC, Matute JC, Tellez Y, Saborío S, et al. Trends in patterns of dengue transmission over 4 years in a pediatric cohort study in Nicaragua. J Infect Dis 2010; 201:5-14.

2. Barros AC, Santos K, Massad E, Coelho FC. Impact of sexual transmission to sex-specific attack rates in Zika epidemics. BioRxiv 347104 [Preprint]. 2018. https://doi. org/10.1101/347104 (accessed on 05/Oct/ 2018).

3. Azevedo MBD, Coutinho MSC, Silva MAD, Arduini DB, Lima JDV, Monteiro R, et al. Neurologic manifestations in emerging arboviral diseases in Rio de Janeiro City, Brazil, 20152016. Rev Soc Bras Med Trop 2018; 51:347-51. 